\title{
Specifics of applying mechanisms of public- private partnership when selecting investment projects
}

\author{
Natalya Moiseenko ${ }^{1, *}$ \\ ${ }^{1}$ State University of Management, Ryazanskiy prospect, 99, Moscow, 109542, Russia
}

\begin{abstract}
The article highlights the issues of selection of public-private partnership (PPP) projects, project ranking and recommended form and implementation scheme. Despite the fact that PPP approach is widely used all over the world, there is no unified classification of its forms, tools, models, types and methodology of adoption. The article lists the key points of selection of PPP projects and constraints, which arise during selection process. Specifics of implementation of different forms of PPP are described under condition of various factors. Prerequisites for the use of one of the form are presented. Several recommendations on project financing are given.
\end{abstract}

\section{Introduction}

The concept and mechanisms of public-private partnerships have been long deeply seated and used in world practice of attracting private companies for long-term financing of public infrastructure and management of it, including a wide range of facilities - transport, utility services, health care, socially significant facilities etc. But at the same time, a unified algorithm for implementing PPP projects and classification of their forms, mechanisms, models and types were not created neither in Russia nor abroad. Moreover, these categories intersect in the literature.

For a more in-depth description of PPP, let's focus on the main issues that need to be addressed when carrying out PPP projects. Before selecting the form of project implementation and the financing scheme, a detailed analysis of proposals is required to be conducted by experts to make a decision on the implementation of a project. There should be solved two main tasks to estimate the project. Firstly, the project must satisfy all the necessary constraints on PPP projects. Secondly, it is necessary to evaluate the contribution of this project to the economy and other spheres of public life in the country due to the scale of projects of this type. Quantitative constraints come first to be met. Thus, the Government Decree "On Approval of the Rules for the Formation and Use of Budgetary Allocations of the Investment Fund of the Russian Federation" approved the criteria for the selection of projects claiming to receive budgetary allocations at the expense of the Investment Fund (IF) of the Russian Federation:

\footnotetext{
*Corresponding author: na_moiseenko@guu.ru
} 
-the minimum cost of a regional project is 500 million rubles; a nationwide project is 5,000 million rubles;

-the minimum share of private investment is $50 \%$ for regional projects and $25 \%$ for national ones;

- the maximum time to finance a project at the expense of the Investment Fund is 5 years;

-the volume of budget allocations for regional projects is limited by quota.

In addition, there are other quantitative and qualitative constraints, that are related with assessing the efficiency of projects, with matching the program priorities for the medium term; the project should have positive social influences, the presence of a favorable conclusion from an investment adviser, a private partner, and so on [1].

\section{Materials and Methods}

These criteria are valid for the state party. Considering private sector, in addition to the above criteria for the volume of initial investments and terms, there is the main one - this is the financial rate of return. Moreover, transparency and accuracy of the process of allocating the budget funds throughout the life of the project should be guaranteed for the business.

The question of the project's relevancy for socio-economic development is solved through the creation of an integrated project evaluation using a cost-benefit analysis (CBA) scheme. The goal of the CBA is to determine whether the project is desirable from the point of view of social welfare, by the algebraic sum of the economic costs and benefits of the project, discounted according to time. The technique used is based on project economic impact prediction; appropriate counting procedures; monetary terms, where it is possible to use traditional ways to express economic effects in numbers; the calculation of profit, using a clear indicator that allows to state an opinion on the efficiency of the project. The main advantage of CBA in comparison with other traditional methods of financial estimate is that external factors and observable price disparities are also considered. Thus, market defects are taken into account in detail, which are not reflected in the corporate accounting, or, as a rule, in the systems of national accounts [2].

Therefore, after evaluating the proposed options, a necessity to select several from a number of projects arises, when a plan for financing PPP projects is formed. Despite the fact that the project may be financially efficient, in practice there is a number of constraints that prevent the implementation of some. In addition, there is a problem to set a rational sequence of objects included in the investment program. Thus, regarding the conducted estimates, a decision is made to include a project in the investment portfolio after analyzing one for all existing limitations. In order to determine the priority (ranking) of projects, expert models of decision-making are used, in particular, a multifactorial model for evaluating a project on a scaling basis. This model is more accurate and correct due to a certain rating of the quality of each specific factor (criterion). It involves a ranking system of assessments of each of the criteria under consideration, that is included in the general list. For investment projects, a final list of general and private estimated indicators is formed, when each of them receives its own value of the weight coefficient of significance (average value for the group of experts). The integral estimate of the project occurs by summing the products of the value of the criterion estimate and its weight. In authors' opinion [3], the list of criteria by which the project will be estimated and selected for implementation within PPP should be the following:

1. Indicator of the project feasibility, its compliance with quantitative and qualitative constraints.

2. Indicator characterizing the financial efficiency of the project. 
3. Indicator characterizing the economic efficiency of the project.

4. Indicator characterizing the social efficiency of the project.

4. Indicator characterizing the acceptability of the risk level of the project.

5. Qualitative indicators:

1) Degree of achievement of the project goal

a) For infrastructure projects

- indicator characterizing the increase in the density of highways in the region;

- increase in the length of railway tracks;

- increase in the length of main pipelines;

- increase in the share of settlements with transport hubs, etc.

b) For innovative projects

- indicator characterizing the innovativeness of the goods or services produced (products undergo significant technological changes or are reintroduced; products undergo improvement; products are manufactured without improvement);

- increase in patent applications;

- increase in patents issued for inventions;

- increase in technology export in value terms;

- increase in the share of organizations engaged in technological innovation, in the total number of industrial production organizations, etc.

c) For small business support projects

- increase in the number of small enterprises in the region by type of economic activity covered by the project under consideration;

- increase in the number of employees of small enterprises in the region;

- increase in the share of small business in the gross regional product, etc.

d) For social projects

- indicator characterizing the multiplier of industry effects;

- indicator characterizing the local political effect.

2) Indicator characterizing the number of additionally created jobs;

3) Indicator characterizing the degree of improvement of the environmental situation;

4) Increase of competitiveness in the industry in connection with the implementation of the project

5) Improvement of the living standards of the population, providing the population with comfortable housing, increasing the availability and quality of public transport, health care, education, social support, physical education and sports, culture, utility services

6) Positive external effect for adjacent branches of the economy, development of financial markets

7) Elimination of infrastructure growth restrictions

8) Increase in the use of natural resources

9) Modernization and development of high-tech industrial production

10) Surge of foreign economic activity

After a portfolio of investment projects has been prepared for implementation within the framework of a PPP project, it is necessary to select the form of a PPP. The classification is based on the type of an ownership and the opportunity to run it. PPP forms include concessions (of various organizational types), leasing, production sharing agreement, state contract, service contract, management contract, public service and works contract, contract for investment or construction, contract for technical assistance, contract for operation and transfer, state audit of PPP facilities, equity participation of private capital in state-owned enterprises (joint ventures), state corporations, holding companies, trust funds, special economic and other zones, investment funds (including venture capital), PPP in the political sphere. The list remains open. The above classification can be grouped both with a reduction in the number of PPP forms and supplemented with new forms of it. In particular, 
new forms may appear with the development of PPP at the regional (subfederal) and municipal levels [4].

\section{Results}

The results of studies of Russian and foreign scientists [1, 4, 5, etc.] indicate that lots of factors influence the choice of a suitable PPP option. It is based on the analysis of the available options for PPP; technical constraints and sector objectives; legal and regulatory restrictions; institutional issues; commercial, financial issues and funding requirements and constraints; interests of the market (local and international); sector specific requirements, based on characteristics of the system or population.

If technical, legal and regulatory restrictions are considered, then one of the first questions is to determine the opportunity of private ownership of objects, due to the fact that the current legislation contains a number of prohibitions and restrictions. For instance, the land under main supply lines and related objects may only be in federal ownership; the law establishes a special procedure for the provision of such land plots on the basis of a leasehold right. So, in cases of transferring the rights of private property to the investor, it is possible to use the ROOT model ("reconstruct, operate on the right of ownership, transfer of the object"), BOO ("build, own, operate"), BOOT ("build, own, operate, transfer") and concession models: BOT ("build, operate, transfer"), BLT (" build of the facility, lease, subsequent transfer "), DBFOT ("design, build, finance, operate, transfer"), ROT ("reconstruct, operate, transfer"). In cases when it is impossible to transfer the rights, in addition to the above models, D\&B models ("design and build") or DBM ("design, build, maintain"), O\&M ("operate and maintain"), S\&M ("service and management") are used [5].

Sector objectives also define specific forms of PPP. For instance, "build, own, transfer" and similar mechanisms are more often involved in the development of toll roads or wastewater treatment plants, when management contracts can be met in the field of health or social care for certain age groups. For the transport sector, the most applicable are the models of the concession agreement, long-term contracts or life cycle contracts (LLC), long-term value investment agreements (LTV). In the social sector, the traditional model is the conclusion between the public authority (regional or municipal) and the developer of the investment agreement [6].

The selection of PPP option is also influenced by specific goals of the government. Depending on the goals, various options may be more suitable to achieve them in a project. Each form of PPP has a set of prerequisites for successful implementation. For instance, indepth forms, when private sector is more exposed, will require more complex legal and regulatory structures, as well as the presence of local skills in the implementation and monitoring of transactions. Other limitations may be low rates of cost recovery, lack of system information, or poor technical execution. If there are no prerequisites, then it may be wiser to start with a less comprehensive form of PPP.

A specific option, such as a concession, may best meet the goals of the government, but the level of risk may be unacceptable for potential private investors. The likely level of interest can be estimated by analyzing previous investments in the region, country, sector, as well as by assessing market interest. Prior to the formal procurement process, potential tenderers are often invited to submit comments on the proposed project design.

There are certain prerequisites for the selection of PPP options. Thus, the services contract involves low political commitment, low regulatory framework, and the average government capacity for contracting, management, and analysis. Management contract has a medium political commitment, medium regulatory framework and average government capacity for contracting, management and analysis. Leases involve medium political 
commitments, high regulatory frameworks and high government capacity for contracting, management and analysis. The concession and variations of the Build-Operate-Transfer model bring high political commitments, high regulatory frameworks, and high government potential for contracting, management, and analysis.

Based on these criteria, available options can be ranked, and the government can make an informed decision on the PPP strategy to be taken.

The next important question concerns the choice of financing structure for a PPP project. There are three most common structures to fund infrastructure projects: government funding, corporate financing, and project funding. When choosing a structure, the question often arises whether it is worth creating a separate project company for implementation, i.e. use the corporate financing structure or the project one.

The algorithm for evaluating the influence and efficiency of project structuring in a separate project company contains an estimate of the savings on agency costs in the framework of interactions between managers and shareholders of the project. In accordance with the proposed algorithm, the project should be implemented using the project funding method if:

1. There is a need to raise capital, which exceeds the financial capacity of the initiator in relation to this project under its terms.

2. There is interest in the project from investors and lenders.

3. The costs of structuring the project do not exceed the benefits from the use of project funding.

\section{Conclusions}

The costs of structuring a project should be of a special focus. The value of the cost of structuring can be obtained by calculating the relevant expense items of the planned costs or using the results of expert estimates.

The benefits of structuring a project in the form of a project company, related to the savings of agency costs, are estimated on the basis of changes in the performance indicators of operating costs and asset turnover of the company depending on the project structuring option:

1. The ratio of operating costs to the revenue of the enterprise: this ratio can be viewed as a characteristic of agency conflicts between management and company owners, showing how much management expenses are paid back, how efficiently managers run the enterprise, whether they are focused on increasing shareholders' incomes.

2. The ratio of revenue to the asset value: in this case, the coverage of agency costs is achieved, which arise from the following reasons:

- incompetence of managers in making investments;

- growth of premiums, bonuses and other additional payments, the acquisition of nonproductive assets in the interests of managers.

The amount of agent costs for the project company must be less than the amount of agent costs for the sponsor corporation, in order to make structuring efficient. To do this, the following conditions must be met:

1. the ratio of the operating costs to the revenue of the project company is less than the ratio of the operating costs to the revenue of the sponsor one;

2. the ratio of the revenue to the asset value of the project company is more than the ratio of the revenue to the asset value of the sponsor one [7]. 
Nevertheless, all of the above is a recommendation. PPP projects are often complex, unique projects with a long implementation period. Therefore, each of them requires its own approach and in-depth analysis to select the form of implementation and financing structure.

\section{References}

1. A. Larionov, Journal of Applied Sciences 14, 2374-2379 (2014)

2. Y. Panibratov, A. Larionov, Applied Mechanics and Materials 725 - 726, 1007-1012 (2015)

3. P. Love, D. Edwards, Z. Irani, IEEE Transactions on Engineering Management 59(4), 6032087, 560-571 (2012)

4. E. Frolova, Sotsiologicheskie Issledovaniya 12, 51-58 (2014)

5. B. Semaan, J. Hemsley, ISCRAM 2015 Conference Proceedings - 12th International Conference on Information Systems for Crisis Response and Management, 321-328 (2015)

6. A.K. Orlov, MATEC Web of Conferences 106, 08013 (2017)

7. A. Mottaeva, MATEC Web of Conferences, 170, 01053 (2018) doi:10.1051/matecconf/201817001053 